\title{
Potential Inhibition of Filamentous Microorganisms in Sludge Bulking by Static Magnetic Field
}

\author{
Nur Syamimi Zaidi ${ }^{1,2 *}$, Khalida Muda $^{1,2}$, Norelyza Hussein ${ }^{1,2}$, Mika Sillanpää $^{3}$ \\ ${ }^{1}$ Faculty of Civil Engineering, Universiti Teknologi Malaysia, 81310 UTM Johor Bahru, Johor, MALAYSIA \\ ${ }^{2}$ Institute of Environmental and Water Resource Management (IPASA), Universiti Teknologi Malaysia, 81310 UTM Johor Bahru, Johor, \\ MALAYSIA \\ ${ }^{3}$ Laboratory of Green Chemistry, Lappeenranta University of Technology, Patteristonkatu 1, 50100 Mikkeli, FINLAND \\ *Corresponding author E-mail: nursyamimi@utm.my
}

\begin{abstract}
In activated sludge system, the performance of the process largely depends on the balance between filamentous and floc-forming microorganisms. When the normal balance of these biological communities is disturbed, filamentous microorganisms tend to proliferate, causing various problems to the treatment performances such as sludge bulking. Various approaches have been used to control the proliferation of filamentous microorganisms. However, the approaches led to various drawbacks that eventually worsen the performances of treatment systems. Therefore, this study is aimed to investigate the potential approach using static magnetic field in inhibiting filamentous microorganisms that presence in the sludge bulking. Magnetic field of intensity $88 \mathrm{mT}$ was used. Its exposure on the filamentous microorganisms was investigated in terms of filaments' characteristics such as branching, shape and filaments' location. The analysis indicated that the magnetically exposed activated sludge showed less possibility presence of the filamentous microorganisms compared to unexposed activated sludge.
\end{abstract}

Keywords: Activated sludge, Filamentous microorganisms, Magnetic field, Sludge bulking.

\section{Introduction}

In activated sludge system, the performance of the treatment process largely depends on the balance between filamentous and flocforming microorganisms [11]. When the normal balance of these biological communities is disturbed, filamentous microorganisms tend to proliferate, causing various problems. Sludge bulking phenomena is one of the major problems referred usually resulting in poor settleability and low quality of the final effluent $[2,9]$. There are more than 20 types of filamentous morphotypes presence in activated sludge biomass [1,13]. Among the common morphotypes are Microthrix parvicella, Types 0092, Sphaerotilus natans and many more. Morphotypes of the filamentous microorganisms are varies depending on the operational nature of the treatment plants.

In order to control the proliferation of filamentous microorganisms, various approaches have been implemented such as by adding chlorine, metal salts or by maintaining higher dissolved oxygen (DO) concentration throughout the treatment process [4]. However, these approaches exhibited certain drawbacks despite the ability of controlling the proliferations. Due to such matter, an approach using magnetic field is seen as a potential application to inhibit the growth of the filamentous microorganisms. Based on the previous researches, application of magnetic field showed good improvement on the activated sludge treatment system through the enhancement of biomass [8,7,17], bacterial activity $[3,15]$ and sludge settleability $[12,14,16]$. Nevertheless, previous researchers in investigating the effect towards such performances used various ranges of magnetic field intensity. This may suggest that different microorganisms have their unique level of magnetic susceptibility. The microorganisms may act differently, either being inhibited or enhanced, similar to the filamentous microorganisms.

To recent knowledge, there are no confirmed findings on the suitable condition of magnetic field that can inhibit the filamentous microorganisms. Therefore, this study is aimed to investigate the susceptibility of the present filamentous microorganisms in the induced condition of activated sludge bulking with respect to the $88.0 \mathrm{mT}$ magnetic field intensity. The susceptibilities are been investigated in terms of filamentous microorganisms' characteristics such as its branching, shape and filament's location.

\section{Materials and Methods}

\subsection{Experimental Setup and Operational Conditions}

Two lab-scale sequencing batch reactors - Reactor $\mathrm{A}\left(\mathrm{SBR}_{\mathrm{A}}\right)$ and Reactor $B\left(S_{B} R_{B}\right)$ were designed with a working volume of $6 \mathrm{~L}$. $\mathrm{SBR}_{\mathrm{A}}$ was equipped with the magnetic device while $\mathrm{SBR}_{\mathrm{B}}$ acted as a control system. The magnetic device that attached to the SBRA comprised series of permanent magnets arranged in an alternate order. Each permanent magnet was a square prism with two faces of $100 \mathrm{~mm} \times 50 \mathrm{~mm}$ and a thickness of $5 \mathrm{~mm}$. The applied magnetic field was at intensity of about $88.0 \mathrm{mT}$. $\mathrm{SBR}_{\mathrm{A}}$ and $\mathrm{SBR}_{\mathrm{B}}$ were operated in parallel with hydraulic retention time (HRT) of 8-h in 3 successive cycles. Each cycle comprised of 10 min filling, $380 \mathrm{~min}$ reaction, $80 \mathrm{~min}$ settling and 10 min decanting. The volumetric exchange rate (VER) was fixed at 50\%. Both reactors were inoculated with activated sludge from a municipal 
wastewater treatment plant and fed with raw domestic wastewater from the same treatment plant. In order to study the characterization of the filamentous microorganisms, both reactors were set to allow sludge-bulking occurrence by slowly reducing the dissolved oxygen (DO) concentration to below than $2 \mathrm{mg} / \mathrm{L}$.

\subsection{Analytical Methods}

Filamentous colonies were identified by direct observation of inoculated plates. The plates were incubated and observed for fast and confluent growth of up to 72 hours. The microscopic characterizations of the filamentous isolates were then performed using phase-contrast high power microscope at 1000x magnification.

\section{Results and Discussions}

A total of 10 filamentous microorganisms have been successfully isolated from the induced activated sludge bulking in the bioreactor system. Out of 10 filamentous, 5 of them were isolated from the raw activated sludge, 2 were isolated from the sludge in $\mathrm{SBR}_{\mathrm{A}}$ and the remaining 3 were isolated from the sludge in $\mathrm{SBR}_{\mathrm{B}}$. All of the 10 filamentous microorganisms were characterized in terms of branching, filament's shape, filament's location as well as filament's width and length. The filamentous isolates were named accordingly as $F M 1_{\text {raw }}-F M 5_{\text {raw }}, F M 6_{R A^{-}} F M 7_{R A}$ and $F M 8_{R B^{-}}$ $F M 1 O_{R B}$. Table 1 shows the results of the morphology and cellular characterization of the isolated filamentous microorganisms from the activated sludge.

Table 1: Morphological and cellular characterization of the ten isolated filamentous microorganisms from activated sludge

\begin{tabular}{|c|c|c|c|c|}
\hline $\begin{array}{c}\text { Filamentous } \\
\text { Strain }\end{array}$ & Branching & Shape & $\begin{array}{l}\text { Filament's } \\
\text { Location }\end{array}$ & $\begin{array}{l}\text { Filament's } \\
\text { Dimension }\end{array}$ \\
\hline$F M 1_{\text {raw }}$ & $\begin{array}{c}\text { Present } \\
\text { (False } \\
\text { branching) }\end{array}$ & Coiled & Free floating & $\begin{array}{c}\mathrm{W}=<1.5 \\
\mu \mathrm{m}\end{array}$ \\
\hline$F M 2_{\text {raw }}$ & $\begin{array}{c}\text { Present } \\
\text { (False } \\
\text { branching) }\end{array}$ & $\begin{array}{c}\text { Irregularly } \\
\text { shaped } \\
\text { chain of } \\
\text { cells }\end{array}$ & Within floc & $\begin{array}{c}\mathrm{W}=<1.0 \\
\mu \mathrm{m} \\
\mathrm{L}=10.0- \\
30.0 \mu \mathrm{m}\end{array}$ \\
\hline$F M 3_{\text {raw }}$ & Absent & $\begin{array}{c}\text { Irregularly } \\
\text { shaped } \\
\text { chain of } \\
\text { cells }\end{array}$ & N/A & N/A \\
\hline$F M 4_{\text {raw }}$ & Absent & $\begin{array}{c}\text { Irregularly } \\
\text { shaped } \\
\text { chain of } \\
\text { cells }\end{array}$ & N/A & N/A \\
\hline$F M 5_{\text {raw }}$ & Absent & $\begin{array}{c}\text { Irregularly } \\
\text { shaped } \\
\text { chain of } \\
\text { cells } \\
\end{array}$ & N/A & N/A \\
\hline$F M 6_{R A}$ & Absent & Straight & $\begin{array}{c}\text { Free floating } \\
\text { (Dispersed) }\end{array}$ & $\begin{array}{c}\mathrm{W}=<1.0 \\
\mu \mathrm{m}\end{array}$ \\
\hline$F M 7_{R A}$ & Absent & $\begin{array}{c}\text { Irregularly } \\
\text { shaped } \\
\text { chain of } \\
\text { cells }\end{array}$ & Free floating & $\begin{array}{c}\mathrm{W}=<1.0 \\
\mu \mathrm{m}\end{array}$ \\
\hline$F M 8_{R B}$ & $\begin{array}{c}\text { Present } \\
\text { (True } \\
\text { branching) }\end{array}$ & $\begin{array}{c}\text { Mycelial; } \\
\text { Coiled }\end{array}$ & $\begin{array}{c}\text { Extending } \\
\text { from floc } \\
\text { surface }\end{array}$ & $\begin{array}{c}\mathrm{W}=2.0- \\
4.0 \mu \mathrm{m}\end{array}$ \\
\hline$F M 9_{R B}$ & Absent & $\begin{array}{c}\text { Irregularly } \\
\text { shaped } \\
\text { chain of } \\
\text { cells }\end{array}$ & N/A & N/A \\
\hline$F M 10_{R B}$ & Absent & $\begin{array}{c}\text { Irregularly } \\
\text { shaped } \\
\text { chain of } \\
\text { cells }\end{array}$ & $\begin{array}{c}\text { Free floating } \\
\text { (Dispersed) }\end{array}$ & $\begin{array}{c}\mathrm{W}=<1.0 \\
\mu \mathrm{m}\end{array}$ \\
\hline
\end{tabular}

In terms of branching, the characterization is divided into two, whether it is present or absent and, if present, whether it is true or false. Based on Table 1, two of the filamentous isolates from raw activated sludge - $F M 1_{\text {raw }}$ and $F M 2_{\text {raw }}$ indicated false branching, while the other three isolates were branch absent. Similar observation of the branch absent was also shown by the filamentous isolates from $\operatorname{SBR}_{\mathrm{A}}\left(F M 6_{R A}\right.$ and $\left.F M 7_{R A}\right)$. Magnetic field exhibited in $\mathrm{SBR}_{\mathrm{A}}$ may inhibit the proliferation of filamentous microorganisms by shortening their branch. This may explained the observation of branch absent for both isolates of $\mathrm{SBR}_{\mathrm{A}}$. For the sludge in $\mathrm{SBR}_{\mathrm{B}}$, one of the isolates $-F M 8_{R B}$ indicated true branching, while the other two isolates were branch absent. The false and true branching observed in $F M 1_{\text {raw }}$ and $F M 8_{R B}$ were indicated in Fig. 1 and Fig. 2, respectively.

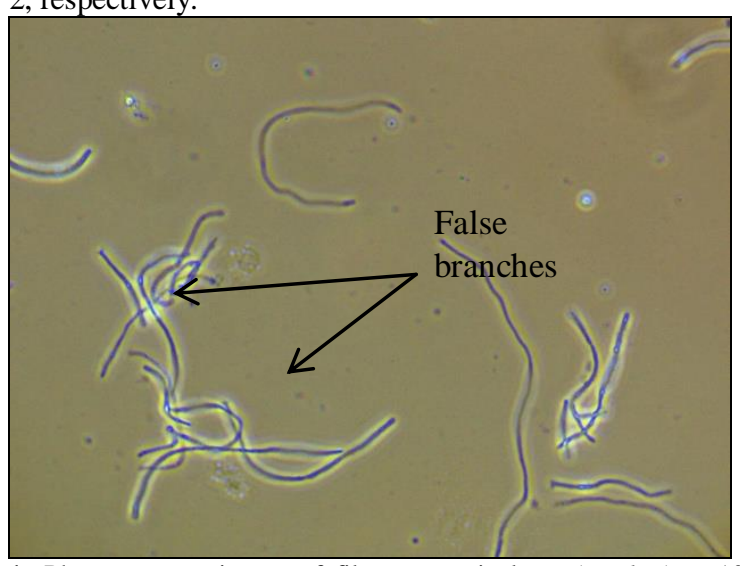

Fig. 1: Phase-contrast image of filamentous isolates $\left(F M 1_{\text {raw }}\right)$ at $1000 \mathrm{x}$ magnification

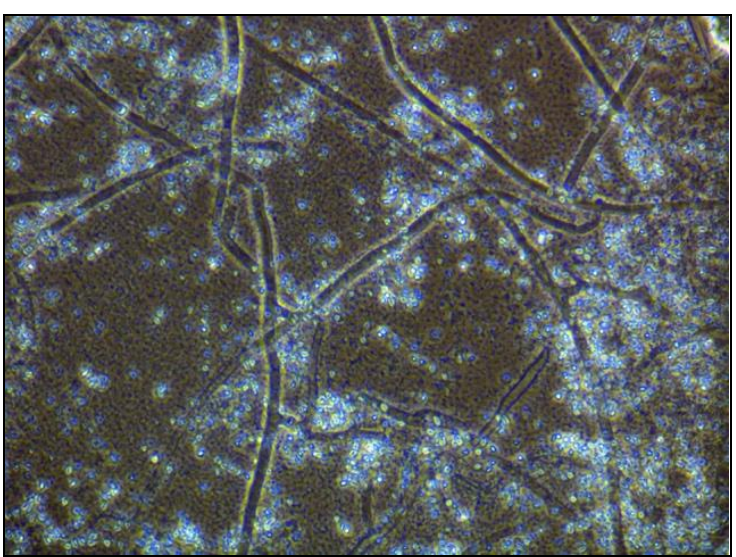

Fig. 2: Phase-contrast image of filamentous isolates $\left(F M 8_{R B}\right)$ at $1000 \mathrm{x}$ magnification

There is slight difference between true and false branching. True branching shows contiguous cytoplasm between branched filaments while false branching occurs when no contiguous cytoplasm is present between filaments. In false branch, two filaments have merely stuck together and grown outward. Commonly, the only filament-forming organisms that have true branches are fungi and nocardioform organisms while for false branches, they are usually observed on Sphaerotilus natas [5]. Eventually, both types of branches exhibited same effect towards the sludge-bulking occurrence. These branches prevent close packing of activated sludge flocs, thus adversely affect the settleability properties $[5,10]$. That is why those two branches were seen in the isolates of raw activated sludge and sludge in $\mathrm{SBR}_{\mathrm{B}}$ rather than sludge in $\mathrm{SBR}_{\mathrm{A}}$. This observation suggested that occurrence of sludge bulking in $\mathrm{SBR}_{\mathrm{A}}$ may have been mitigated by the magnetic field.

In terms of filament's location, most of the isolates were free floating and dispersed. Only $F M 8_{R B}$ (Fig. 2) was seen protruding from the floc surface and filaments' isolates of $F M 2_{\text {raw }}$ (Fig. 3) was observed within the floc. The filament's location could indicate the severity of sludge bulking. Filaments that intertwined inside the floc or protruding from the floc surface are potential to cause severe bulking [5-6], thus showing that $\mathrm{SBR}_{\mathrm{B}}$ was more problematic than $\mathrm{SBR}_{\mathrm{A}}$. These characterizations were made based on the classification reported by Jenkins et al. [5]. 


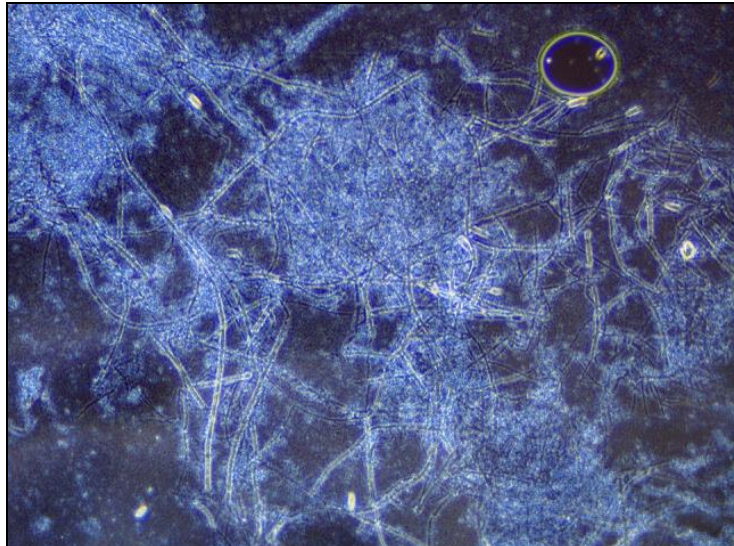

Fig. 3: Phase-contrast image of filamentous isolates $\left(F M 2_{\text {raw }}\right)$ at $1000 \mathrm{x}$ magnification

As for filament's shape, most of the isolated filamentous were observed as irregularly shaped chains of cells. Only three isolates, which are $F M 1_{\text {raw }}, F M 8_{R B}$ and $F M 6_{R A}$ were in different shape which are coiled, mycelial and straight, respectively. However, these shapes are not much affect the condition of bulking [5] However, in comparison between straight-shaped of filaments than other shapes, straight-shaped (as indicated by filament isolates of $\mathrm{SBR}_{\mathrm{A}}$ ) was likely to contribute less to the sludge bulking. Such shape may disable the filaments to form bridging within other filaments. That is why $\mathrm{SBR}_{\mathrm{A}}$ showed less bulking symptom compared to $\mathrm{SBR}_{\mathrm{B}}$

In terms of filament's width, categorization of more than $1 \mu \mathrm{m}$ is considered as thick filament while less than $1 \mu \mathrm{m}$ is considered as thin filament [5]. Based on the phase-contrast observation, isolates from $\mathrm{SBR}_{\mathrm{A}}$ indicated thin filament with the average width and length of approximately less than $1 \mu \mathrm{m}$ and less than $10 \mu \mathrm{m}$, respectively. Meanwhile for the isolates from $\mathrm{SBR}_{\mathrm{B}}$, one of it showed thick filament with the average width ranging from 2 to 4 $\mu \mathrm{m}$. The effect of magnetic field in $\mathrm{SBR}_{\mathrm{A}}$ may limit the growth of the filamentous microorganisms thus resulted in thin filaments as been observed. As for $\mathrm{SBR}_{\mathrm{B}}$, due to no control measure that has been adopted, the condition of low DO concentration has been well favored by the filamentous microorganisms, hence providing good condition to form thick filaments. Filipič et al. [3] reported that the use of magnetic field had negatively affected the growth, but at the same time positively affect the enzymatic activity of Escherichia coli and Pseudomonas putida. This report strongly support the findings in this study at which application of $88.0 \mathrm{mT}$ magnetic field intensity has inhibit the growth of filamentous microorganisms but at the same time, enhanced the activity of other aerobic microorganisms that beneficial in biodegradation processes.

Throughout the above characterizations, the filamentous isolates from $\mathrm{SBR}_{\mathrm{A}}\left(F M \sigma_{R A}\right.$ and $\left.F M 7_{R A}\right)$ can be concluded in exhibiting less effect to induce the sludge bulking due to its filament's location that were dispersed, thin filaments and absent branching. On the other hand, filamentous isolates from $\mathrm{SBR}_{\mathrm{B}}$ (mostly $F M 8_{R B}$ ) showed a huge potential of sludge bulking as a result of filament's location that extending out from the floc surface, their thick filaments and presence of the true branching.

\section{Conclusion}

The overall characterization generalized that the filamentous isolates under the exposure of magnetic field in $\mathrm{SBR}_{\mathrm{A}}$ were less activated to induce the sludge bulking due to the filament's location that were dispersed, thin filaments and its absent branching. In contrast, filamentous isolates from $\mathrm{SBR}_{\mathrm{B}}$ showed that there is a great potential for the occurrence of sludge bulking as a results of filament's location that extending out from the floc surface, thick filaments and presence of the true branching.

The characterizations also deduced that the proliferations of filamentous microorganisms were adversely affected under the exposure of magnetic field. This suggesting that magnetic field could stand a great chance in eliminating the occurrence of filamentous sludge bulking in activated sludge treatment system.

\section{Acknowledgement}

The authors thank the Universiti Teknologi Malaysia (UTM) for financially supporting this research using Research University Grant (RUG) (Grant No.: 14J41).

\section{References}

[1] De los Reyes FL (2010), Foaming. In: Seviour RJ \& Nielsen PH Microbial Ecology of Activated Sludge (pp. 215-258) London, UK: IWA Publishing.

[2] Ferreira V, Martins C, Pereira MO \& Nicolau A (2014), Use of an aerobic selector to overcome filamentous bulking in an activated sludge wastewater treatment plant. Environmental Technology 35(12), 1525-1531.

[3] Filipič J, Kraigher B, Tepuš B, Kokol V \& Mandic-Mulec I (2012), Effects of low-density static magnetic fields on the growth and activities of wastewater bacteria Escherichia coli and Pseudomonas putida. Bioresource Technology 120, 225-232.

[4] Guo J, Peng Y, Wang Z, Yuan Z, Yang X \& Wang S (2012), Control filamentous bulking caused by chlorine-resistant Type $021 \mathrm{~N}$ bacteria through adding a biocide CTAB. Water Research 46, 6531-6542.

[5] Jenkins D, Richard MG \& Daigger GT (2004), Manual on the cause and control of activated sludge bulking, foaming and other solids separation problems (3rd ed.) Chelsea: Lewis Publishers.

[6] Juang D-F (2005), Effects of synthetic polymer on the filamentous bacteria in activated sludge. Bioresource Technology 96, $31-40$.

[7] Křriklavová L, Truhlář M, Škodová P, Lederer T \& Jirků V (2014), Effects of a static magnetic field on phenol degradation effectiveness and Rhodococcus erythropolis growth and respiration in a fedbatch reactor. Bioresource Technology 167, 510-513.

[8] Łebkowska M, Rutkowska-Narożniak A, Pajor E \& Pochanke Z (2011), Effect of a static magnetic field on formaldehyde biodegradation in wastewater by activated sludge. Bioresource Technology 102(19), 8777-8782.

[9] Lou IC \& De los Reyes III FL (2008), Clarifying the roles of kinetics and diffusion in activated sludge filamentous bulking. Biotechnology and Bioengineering 101(2), 327-336.

[10] Schuler AJ \& Jassby D (2007), Filament content threshold for activated sludge bulking: Artifact or reality? Water Research 41, 43494356.

[11] Tandoi V, Jenkins D \& Wanner J (2006), Activated sludge separation problems. In: Theory, control measures, practical experience London: IWA Publishing.

[12] Wang X-H, Diao M-H, Yang Y, Shi Y-J, Gao M-M \& Wang S- G (2012), Enhanced aerobic nitrifying granulation by static magnetic field. Bioresource Technology 110, 105-110.

[13] Wanner J, Kragelund C \& Nielsen PH (2010), Microbiology of bulking. In: Microbial ecology of activated sludge London: IWA Publishing.

[14] Xu YB, Duan XJ, Yan JN \& Sun SY (2009), Influence of magnetic field on $\mathrm{Cr}$ (VI) adsorption capability of given anaerobic sludge. Biodegradation 21(1), 1-10.

[15] Yin X, Qiao S \& Zhou J (2015), Using electric field to enhance the activity of anammox bacteria. Applied Microbiology and Biotechnology 99, 6921-6930.

[16] Zaidi NS, Muda K, Sohaili J \& Sillanpää M (2014), Optimization of activated sludge physical properties by magnetic field via response surface modeling. Applied Mechanics and Materials 567, 98-103.

[17] Zaidi NS, Muda K, Sohaili J, Toemen S \& Yusof NZ (2016), Optimization of operating parameters for aggregation under magnetic field by response surface methodology. ARPN Journal of Engineering and Applied Sciences 11(4), 2419-2425. 